\title{
STUDI TIPOGRAFI KAWASAN DI YOGYAKARTA
}

\author{
Naufan Noordyanto \\ Program Magister Penciptaan dan Pengkajian Seni \\ Minat Studi Desain Komunikasi Visual, Program Pascasarjana ISI Yogyakarta \\ noordbita@gmail.com
}

\begin{abstract}
In recent years, the landscape of Daerah Istimewa Yogyakarta (DIY) enchanced by the presence of three-dimensional (3D) typographical placemaking in some corner of the city or region. The typographical is artworks of architectural design formed in 3D typography as a sign name of the region/place using a particular typeface that displayed at a particular place (usually a public space), and normally a landmark area/place. In because the tendency of typographical placemaking which used to identify a name of a region/place, so in this study, the author simply call it spesifically as region base typography. But, some case of region base typography in some place, the typeface is designed with generic design., planned and designed uniquely or specifically to respond the visual communication problems of the region. In fact, if the visualization (aesthetic element) region base typography represents the values and image of the region, it will be like "a brand that sells" on the region's branding efforts. In addition, if the region base typography created with (the concept of) a good aesthetic and fulfill the functions as a artwork of brand identity design of an area or region, it will be seen and enjoyed the beauty and charm independently as a work of public art, it can even raise interest and attention the discourse of art and typography. As well as the public can know, understand, and remember the uniqueness of typefaces to identify a particular area. Therefore, this study is conducted to review the quality of the artistic and conceptual frame generally on Visual Communication Design (DKV) perspective, particularly in the disciplines of Typography, related an interesting phenomenon where typography iconic charm of the area as a tourist destination.
\end{abstract}

Keywords: typography, placemaking, Yogyakarta, destination, area, region, tourist

\section{PENDAHULUAN}

\section{Latar belakang masalah}

Geliat intervensi artistik lansekap wilayah Daerah Istimewa Yogyakarta (DIY) terus dilakukan Pemerintah. Wajah DIY dalam beberapa tahun ini, dipercantik dengan hadirnya karya placemaking tipografis tiga dimensional (3D) di beberapa sudut kota maupun daerah. Bukan semata-mata sebagai instalasi seni temporer semata, tapi mengindikasikan upaya jangka panjang pemerintah membenahi branding wilayah. Branding wilayah dalam hal ini merupakan aktifitas membangun dan menguatkan brand dengan menguatkan karakter asetnya secara fisik maupun sosio-psikis melalui pembangunan identitas yang jelas, asosiasi yang kuat, dan menyematkan atribut positif, bahkan menawarkan janji-janji positif, sehingga kota mampu menempatkan diri dan memenangkan persaingan dengan wilayah atau daerah lainnya (Yananda dan Salamah, 2014: 55)

Placemaking tipografis yang dimaksud adalah karya desain arsitektural berwujud tipografi 3D, bertuliskan nama kawasan/tempat dengan memakai jenis huruf tertentu yang di-display atau "dipamerkan" pada suatu tempat tertentu (umumnya ruang 
publik), dan biasanya menjadi landmark kawasan/tempat tersebut. Menurut Calori (2015: 4), sifatnya yang mengakuisisi konsep ruang dan lingkungan, placemaking menjadi bagian praktik "environmental graphic design" (EGD). Maka berpijak dari pemahaman tersebut, placemaking tipografis dapat dimasukkan dalam kelompok tipografi spasial (spatial typography) atau $3 D$ environmental typography.

Kecenderungan placemaking tipografis tersebut yang mengidentifikasi nama suatu kawasan/tempat, maka kemudian dalam kajian ini, lebih mudahnya penulis spesifikkan dengan memakai istilah "tipografi kawasan". Selain karena data-data karya yang diulas dalam tulisan ini adalah placemaking tipografis berwujud tulisan nama kawasan, pemakaian istilah 'kawasan' juga merujuk pada Kamus Bahasa Indonesia (KBI) yang didefinisikan sebagai "daerah (sekitar) yang memiliki ciri tertentu”, misalnya dalam hal ini kawasan wisata. Sebagai unit dasar geografis, mengacu pada Encyclopedia Britannicaonline (http://www.

britannica.com/science/region-geography), kawasan merupakan "bagian dari wilayah administratif dan (kekuasan) pemerintahan". Sehingga tipografi kawasan dapat dikatakan sebagai proyek strategis pemerintah dalam membangun image kawasan dan wilayah melalui perancangan public art pada ruang publik.

Di wilayah DIY, persebaran bangunan tipografi kawasan sebagai identitas kawasan wisata biasanya dibangun di kawasan destinasi wisata langsung dan ada pula yang tidak dibangun di kawasan wisatanya langsung, seperti di sekitar jalan utama daerah untuk menandai wilayah administratif wisata.
Tipografi kawasan yang dibangun di kawasan destinasi wisata langsung di antaranya: di Pantai Parangtritis, Puncak Bucu Piyungan, Alun-alun Wates. Sedangkan tipografi kawasan yang tidak dibangun di kawasan destinasi wisata langsung misalnya: di kawasan gerbang Patuk Kabupaten Gunungkidul dan di dekat jembatan Bantar, Sentolo, Kulonprogo. Geliat munculnya fenomena tipografi kawasan tersebut seolah-olah mempertontokan gemuruh daerah-daerah di DIY yang terus berbenah dan berlaga merebut hati calon wisatawan, seperti halnya yang dilakukan Pemerintah di berbagai daerah lain di Indonesia. Dalam hal ini, misalnya sebagaimana diungkap Kepala Kantor Pengendalian Dampak Lingkungan (Kapedal) Kabupaten Gunungkidul dalam Kabarhandayani.com pada 13 Juli 2014 (http://kabarhandayani.com/ikon-barugunungkidul-handayani-sambut-wisatawan2/), terkait fungsi tipografi kawasan untuk menarik wisatawan berkunjung ke Gunungkidul. Sehingga penampilan estetik tipografi kawasan semestinya dihadirkan beda dan dibangun dengan difrensiasi dan keunikan di antara kawasan lainnya yang saling bersaing, tidak hanya untuk mengidentifikasi suatu tempat atau kawasan.

Visualisasi kreatif tipografi kawasan yang khas diupayakan menjadi karakteristik khas dari suatu kawasan sehingga dapat memberi preferensi/pilihan/kecenderungan bagi masyarakat untuk mengenali suatu kawasaan di mana lokasi tipografi kawasan itu berada. Bahkan preferensi tersebut berperan dalam mengarahkan wisatawan untuk menumbuhkan hasrat berkunjung ke lokasi wisata tempat tipografi kawasan itu didirikan, atau ke kawasan wisata di suatu daerah yang 
disimbolkan tipografi kawasan tersebut. Namun, kesadaran akan penampilan estetik atau visualisasi kreatif dan daya tarik imateril/konototatif tersebut seperti kurang dipahami betul, terutama nampak dari beberapa fakta karya-karya tipografi kawasan di beberapa wilayah DIY.

Dalam konteks tipografi kawasan sebagai identitas tipografis (visual), beberapa kasus tipografi kawasan di beberapa tempat, didesain dengan typeface yang generik (umum), bukan direncanakan dan dirancang secara unik atau khusus untuk merespon permasalahan komunikasi visual kawasan itu sendiri. Sebagai contoh tipografi kawasan di Pantai Parangtritis (jenis huruf serif /huruf berkait, menyerupai typeface Times New Roman), dan di kawasan gerbang Patuk Kabupaten Gunungkidul (jenis huruf serif), Puncak Bucu (jenis huruf sans serif/tidak berkait, menyerupai typeface Arial), dan AlunAlun Wates (jenis huruf sans serif menyerupai typeface Calibri). Bahkan di beberapa tempat tersebut, misalnya tipografi kawasan di Pantai Parangtritis dan Gerbang Patuk, didesain dengan penampilan visual huruf yang cenderung mirip dan serupa karena karakter artistik tipografinya yang terlampau umum, dan tidak mencerminkan keunikan entitas (wilayah). Padahal eksplorasi tipografi dapat dipakai untuk menekankan difrensiasi dan mampu memberikan kekhasan dengan kawasan lain. Sehingga mudahnya masyarakat dapat mengetahui, mengerti, dan mengingat kekhasan tipografi tersebut untuk mengidentifikasi suatu daerah tertentu.

Berpijak dari masalah tersebut, ulasan dalam tulisan ini tidak berambisi untuk melakukan analisis mendalam tentang strategi branding DIY. Tetapi berupaya melakukan kajian kualitas artistik dan konseptual secara garis besar dalam bingkai disiplin Desain Komunikasi Visual (DKV) khususnya dalam ranah disiplin Tipografi, terkait fenomena menarik keberadaan tipografi kawasan sebagai pesona ikonik destinasi wisata. Sebagai pendekatan, tulisan ini mengacu pada pandangan kritis Bettina Reiber dalam artikel yang ditulisnya "Psyche, Imagination and Art" (Rowland, 2008: 66-74). Riber menyatakan ketidaksetujuannya terhadap studi dan pembicaraan seni yang didominasi pelbagai pendekatan konteks dan wacana di luar seni, bukan ditekankan terhadap kualitas dan substansi dari karya seni itu sendiri (Rowland, 2008: 69). Oleh karena itu, kajian kualitas artistik dan konseptual secara garis besar tipografi kawasan ini lebih didominasi oleh ulasan artistik daripada konteks dan wacana di luar harya, mengingat tipografi kawasan sebagai karya desain arsitektural tidak terlepas dari ruang dan masyarakat.

\section{Rumusan Masalah}

Adapun rumusan masalah dari kajian ini yaitu: bagaimanakah penampilan estetik tipografi kawasan di beberapa titik kawasan DIY? Bagaimanakah upaya pemecahan masalah atas permasalahan estetik tipografi kawasan di beberapa titik kawasan DIY tersebut?

\section{Batasan masalah}

Kajian ini dititikberatkan pada kajian kualitas artistik dan konseptual secara garis besar dalam bingkai disiplin Desain Komunikasi Visual (DKV) khususnya dalam ranah disiplin Tipografi, khususnya tipografi kawasan di beberapa wilayah DIY. 


\section{Metode penelitian}

Metode pengumpulan data dilakukan dengan observasi, dokumentasi, serta studi literatur terkait berbagai sumber tertulis yang relevan dengan kajian, baik melalui penelusuran dokumen fisik maupun elektronik (misalnya: berita online). Metode analisis dilakukan dengan analisis kualitatif deskriptif.

\section{PEMBAHASAN DAN HASIL PENELITIAN}

\section{Dualitas Nilai Tipografi Kawasan dalam Fungsinya sebagai Identitas}

Berdasarkan Klimchuk dan Krasovec (2012: 65), secara etimologi, istilah tipografi sendiri berasal dari bahasa Yunani, yaitu "typo" berarti impresi (impression), dan "graphein" berarti menulis (to write). Tipografi menekankan penggunaan bentuk huruf untuk mengkomunikasikan secara visual suatu bahasa verbal. Dalam konteks tipografi kawasan, huruf sebagai fokus perhatian tipografi, dipandang dari segi bentuk (karakter visual), karakter nonfisiknya (aura huruf), hingga aspek teknikal dan konseptualnya.

Dari sisi material diamati bagaimana bahan pembuatan tipografi kawasan yang umumnya di luar ruang ini dibuat agar kuat, tahan lama, memunculkan kesan tertentu. Dalam perspektif sosio-kultural, dilihat bagaimana bangunan arsitektural tipografi kawasan memberikan dampak bagi masyarakat sekitar, mengingat karya tersebut tidak lepas dari interaksi masyarakat terhadap karya. Sementara dari sisi konseptual dan fungsi, dikaji bagaimana tipografi macam ini menjadi landmark strategis sebagai instrumen identitas dalam mendukung branding kawasan. Menurut penulis, aspek-aspek itulah yang minimal diperhitungkan sebagai indikator minimal terkait kedalaman dan kualitas karya dalam membuat dan mengkaji desain tipografi kawasan.

Konsep placemaking umumnya dibuat sebagai citra/bentuk ikonik khas, identitas unik, dan dapat dimengerti/dipahami (kekhasannya) dari sebuah tempat, sehingga membentuk citra brand yang mengakomodasi lingkungan/ kawasan tersebut (Calori 2015: 6). Mengacu dari pemahaman tersebut, sebagai tipografi spasial, tipografi kawasan mengindikasikan fungsi sebagai identifikasi, tanda atau simbol yang merujuk pada aktivitas dan praktik branding wilayah. Hal ini selaras dengan tujuan pembuatan tipografi kawasan yang disampaikan pemerintah wilayah DIY. Misalnya seperti yang diungkap Kapedal Kabupaten Gunungkidul, terkait fungsi tipografi kawasan untuk menarik wisatawan berkunjung ke Gunungkidul, sebagaimana dilansir Kabarhandayani.com $\begin{array}{llll}\text { pada } & 13 & \text { Juli } & 2014\end{array}$ (http://kabarhandayani.com/ikon-barugunungkidul-handayani-sambut-wisatawan2/).

Praktik tipografi kawasan seringkali merupakan perpanjangan terapan konsisten dari identitas visual (logo) suatu kawasan. Berpijak dari hal itu, tipografi kawasan adalah identitas wilayah yang idealnya diciptakan untuk memberikan gambaran tentang brand image bagaimana wilayah tersebut ingin dipersepsikan oleh masyarakat. Konsistensi penerapan identitas dalam branding tersebut penting, apalagi jika identitas itu diaplikasikan dan diadaptasi menjadi sebuah karya tipografi kawasan yang tentunya perlu direncanakan dan tidak asal buat. Maka, menurut penulis sebenarnya karya tipografi kawasan itu mencakup dualitas nilai: pertama, nilai 
materil/inderawi dengan kemampuannya sebagai identitas fisik yang dapat dilihat (karakteristik visual); kedua, nilai immateril/abstrak melingkupi berupa aura/kesan (psikologis), citra (brand image), asosiasi makna, simbolisasi, metafora, representasi nilai-nilai, dll.

Manifestasi prinsip seperti itu, nampak pada penerapan logo pariwisata daerah yang dibuat menjadi tipografi kawasan pada kawasan dekat jembatan Bantar, Sentolo, Kulonprogo. Secara otomatis karakteristik rupa huruf (typeface), ikon, dan asosiasi makna (perlambangan) mengadaptasi konsep logo "Kulonprogo-The Jewel of Java" dan simbol (ikon gunungan wujud semboyan binangun) sebagai representasi nilai-nilai wilayah. Hal ini tidak hanya menunjukkan tapi menegaskan kesadaran pemerintah setempat akan konsistensi penerapan identitas (visual) sebagai wujud profesionalitas dalam branding wilayah.

Dampak positifnya, pemerintah tidak perlu bersusah payah lagi melakukan riset dan ekplorasi visual dari unsur tipografi dan ikon yang akan dipakai. Tetapi lebih pada riset dan studi arsitektural bagaimana tipografi kawasan dan tambahan-tambahan identitas ikonik lain berdasar identitas wilayah dan kondisi geografis akan dibangun. Tipografi kawasan sebagai identitas yang unik dan khas ini tentu merepresentasikan berbagai nilai-nilai yang digali dari potensi wilayah Kulonprogo sebagai identitas branding wilayah.

Ibarat wajah manusia, sebagai identitas fisik yang dapat dilihat, penampilan estetik tipografi kawasan tentu penting dan mempengaruhi kekuatan/aura sebagai daya tarik wisatawan terhadap kawasan tersebut. Selain dimensi estetik huruf, aura dan kesan juga terbentuk dari desain keseluruhan meliputi kondisi arsitektural bangunan dudukan huruf, material bahan, ukuran/dimensi, maupun penempatan dan kondisi tempat dibangunnya tipografi kawasan tersebut sebagai respon kreatif dalam memahami ruang (publik). Aura atau aspek nonfisik/psikologis yang ditebarkan desain tipografi kawasan sebagai identitas layaknya seperti aura dan karisma seseorang, yaitu pancaran energi/kekuatan aktif (aspek nonfisik) yang (berupaya) dimunculkan dalam imajinasi dan persepsi masyarakat atas visualisasi yang nampak. Sekaligus atas refleksi brand image yang dikomunikasikan secara tersirat pada karakter fisik dan visual. Pancaran "energi" ini dapat bersifat positif ataupun negatif.

\section{Identifikasi Karya Tipografi Kawasan}

Tipografi kawasan di wilayah DIY yang berhasil teridentifikasi di antaranya: tipografi kawasan di Pantai Parangtritis; Puncak Bucu Piyungan; Alun-Alun Wates; di kawasan gerbang utama Kabupaten Gunungkidul; dan di dekat jembatan Bantar, Sentolo, Kulonprogo.

Pertama, tipografi kawasan di Pantai Parangtritis. Tipografi kawasan tersebut dihadirkan dengan jenis huruf serif (berkait) menyerupai typeface Times New Roman bertuliskan "PANTAI PARANGTRITIS" dalam huruf kapital. Tiap huruf diatur saling berjejer di atas dudukan bangunan beton/semen yang ditutup ubin di bagian sisi muka dan terdapat ruang ventilasi sepanjang huruf P-G yang dipisahkan dengan sekatsekat. Tipografi kawasan di Pantai Parangtritis yang dibangun sekitar November 2014 lalu ini, dibuat dengan ukuran sekitar 2x25 meter, 
dengan tinggi elemen huruf dan lebar rerata masing-masing huruf serta tinggi dudukan kurang lebih sekitar 1 meter, dan menghabiskan dana sebesar 190 juta sebagaimana diberitakan Kedaulatan Rakyat pada 15 Desember 2014 (http://krjogja.com/ read/ 240899/hore-parangtritis-punya-ikonbaru.kr). Elemen tulisan dipoles dengan cat warna merah kejinga-jinggaan yang mencolok dengan latar pantai. Di bagian space dudukan, di bawah jejeran huruf "RITIS" terdapat logo tipografis kabupaten Bantul kombinasi warna hijau dan jingga beserta slogan "The Harmony of Nature and Culture" dalam huruf kapital jenis sans serif (tidak berkait) warna putih.

Permukaan fisik huruf baik tulisan Parangtritis dan atribut logo Bantul dibuat dari plat logam/besi, sedangkan kerangka besi penyangganya terbuat dari besi tabung dan tampak di sisi bagian belakang huruf tersebut. Penerangan dengan satu lampu sorot yang didirikan dengan tiang bambu. Kondisi terbaru (Desember 2015) tipografi kawasan ini yaitu bagian-bagian huruf sebagian besar sudah tampak berkarat, posisi tegak beberapa huruf sudah tidak teratur/miring, beberapa plat fisiknya sebagian nampak lepas atau tidak menempel lagi, beberapa kerangka besi patah karena korosi, cat luntur, bangunan dudukan huruf banyak coretan vandal, pantai di bagian space logo Bantul meninggi yang sebagian menutupi slogan logo Bantul, serta beberapa huruf slogan tersebut lepas dan hilang.

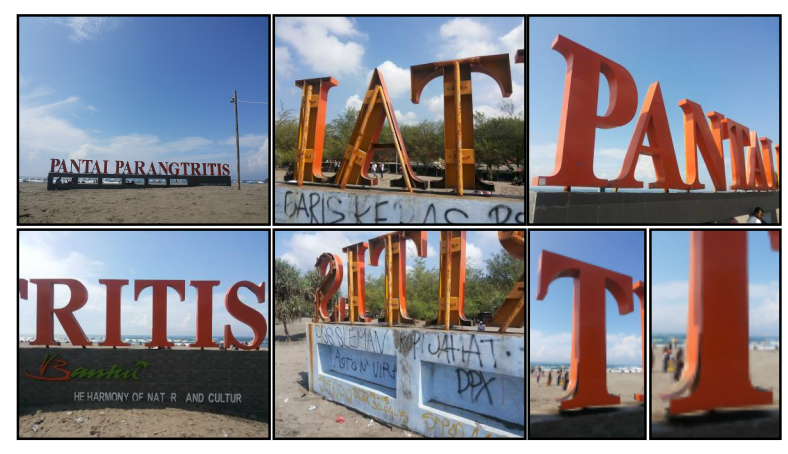

Gambar 1 Tipografi kawasan di Pantai Parangtritis Sumber: Dokumentasi penulis, 2015

Kedua, tipografi kawasan di Puncak Bucu, Piyungan. Meski belum pernah ke lokasi tersebut secara langsung, penulis berhasil mendapatkan data visual dari sosial media pengunjung di dunia maya/internet. Pembangunan fasilitas termasuk tipografi kawasan masih baru-baru ini keberadaannya. Sehingga distribusi informasi terkait berita dan data tipografi kawasan ini, ternyata diketahui masih minim yang tersebar di dunia maya/internet. Dari data visual, nampak tipografi kawasan ini dihadirkan dengan jenis huruf sans serif menyerupai typeface Arial.
Tiap-tiap huruf dijejer membentuk tulisan "PUNCAK BUCU" dalam huruf kapital. Sisi muka dan Belakang dicat warna jingga, sedangkan bagian sisi dalam atau sampingnya dicat warna hijau. Dudukan huruf dibuat $\mathrm{dr}$ susunan batu yang ditata rapi. Diperkirakan berdasarkan (lihat gambar kiri atas, di bawah ini) tinggi huruf sekitar setengah meter-an, sedangkan tinggi dudukan sekitar satu meteran. 


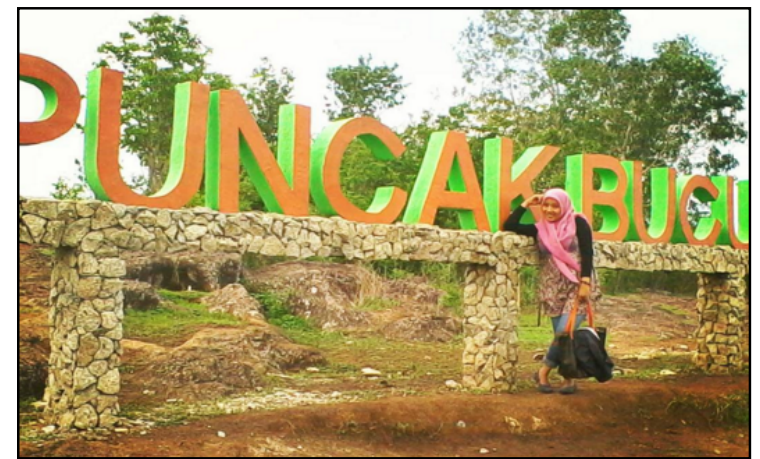

Gambar 2 Perbandingan tinggi tipografi kawasan di Puncak Bucu dengan pengunjung

Sumber: akun instagram @tina_lastafala https://www.instagram.com/p/-uXqDEPvDg/

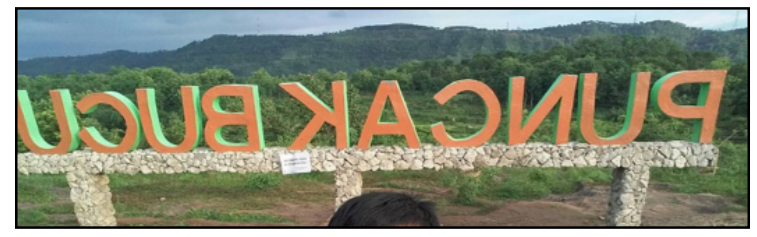

Gambar 3 Panorama di lokasi tipografi kawasan di Puncak Bucu

Sumber: akun instagram @narko_dwi, https://www.instagram.com/p/_wfSX1Tczn/

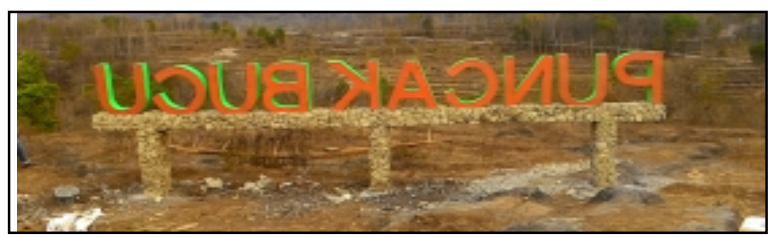

Gambar 4 Panorama di lokasi tipografi kawasan di Puncak Bucu

Sumber: http://berita-

berbeda.blogspot.co.id/2015/10/menikmati-sorehari-di-puncak-bucu.html

Ketiga, tipografi kawasan di alun-alun Wates, Kulonprogo. Tipografi kawasan ini dihadirkan dengan jenis huruf sans serif menyerupai typeface Calibri dalam italic style bertuliskan "Alun-Alun Wates" berwarna merah, dengan diatur berjejer mengikuti sisi kurva/lingkaran air mancur tugu Kulonprogo.

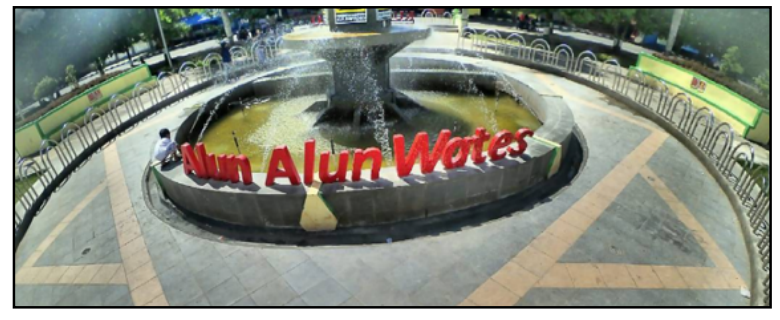

Gambar 5 Alun-Alun Wates Sumber: akun instagram @bay157extrada, https://www.instagram.com/p/_x9t5QpTu9/

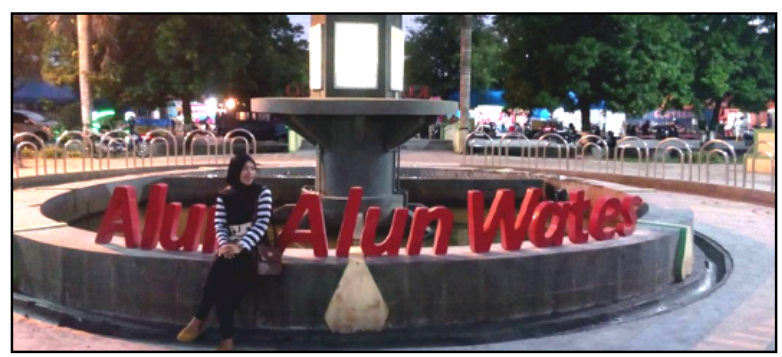

Gambar 6 Alun-Alun Wates

Sumber: akun instagram @mheylhya https://www.instagram.com/p/_wPtJ3EcX9/

Keempat, tipografi kawasan di gerbang Patuk, Gunungkidul yang dibangun pada paruh 2014 lalu. Tinggi dan lebar rerata elemen huruf "GUNUNGKIDUL" kurang lebih 1,5 meter, sementara dimensi tulisan "Handayani" sekitar kurang setengah kali dari panjang dan tinggi elemen tulisan "GUNUNGKIDUL" yang diposisikan di sebelah atasnya. Tipografi kawasan tersebut dihadirkan dengan jenis huruf serif (berkait) menyerupai typeface Times New Roman bertuliskan "GUNUNGKIDUL" dalam huruf kapital dan tulisan "Handayani" dengan jenis huruf script. Berdasarkan laporan berita Kabarhandayani.com pada 13 Juli 2014 (http://kabarhandayani.com/ ikon- barugunungkidul-handayani-sambut-wisatawan-

2/), tipografi kawasan ini dibangun di atas tanah milik Pemkab Gunungkidul seluas 1000 meter persegi dan menelan dana sebesar 180 juta. Tipografi kawasan tersebut dilengkapi lampu penerangan di malam hari. Balutan warna kuning pada elemen huruf, barangkali 
sebagai perlambangan kekayaan potensi Gunungkidul. Sebuah isyarat pada wisatawan agar mengeksplorasi dan jelajah wisata di kabupaten tersebut. Selain itu, di sisi kiri (dari pengamat) bangunan itu, dilengkapi dengan desain arsitektural ikon topeng dengan tinggi yang hampir sama dengan elemen huruf tipografi kawasan, sebagai identitas kesenian daerah dan industri kerajinan rakyat Gunungkidul.

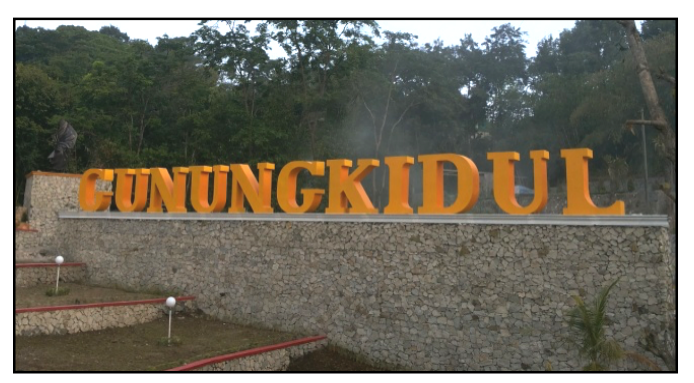

Gambar 7 Tipografi kawasan di gerbang Patuk Gunungkidul

Sumber: Naufan Noordyanto, 2014

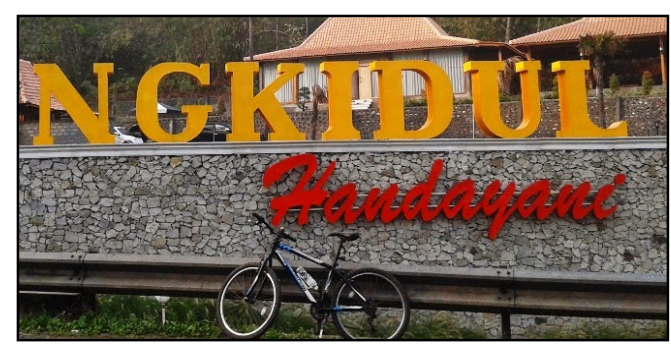

Gambar 8 Tipografi kawasan di gerbang Patuk Gunungkidul

Sumber: http://www.nasirullahsitam.com/2014/12/ mengayuh -pedal-sepeda-ke-embung.html

Kelima, tipografi kawasan di sisi barat jembatan Bantar, Sentolo, Yogyakarta diibuat melalui penerapan terusan dari logo pariwisata daerah. Secara otomatis karakteristik rupa huruf (typeface), ikon, dan asosiasi makna (perlambangan) mengadaptasi konsep logo "Kulonprogo - The Jewel of Java" dan simbol (ikon gunungan wujud semboyan binangun) sebagai representasi nilai-nilai wilayah. Kendati unsur tipografi pada logo kawasan dibalut warna merah (bukan hijau sebagaimana warna logo utama aslinya), bisa jadi hal tersebut karena pertimbangan variasi warna identitas yang lazim dalam penerapan warna identitas (corporate color). Tipografi teks "Kulonprogo" disajikan dengan jenis display type, dekoratif dan mengadaptasi penggayaan script (tulisan bersambung) dengan kombinasi ikonik di huruf "O" dan jenis huruf serif untuk tulisan "The Jewel of Java” yang diposisikan di bagian bawahnya.. Tidak seperti tipografi kawasan yang disebutkan sebelumnya, logotype Kulonprogo "ditempel" pada background yang bermotifkan pola bulatan geblek renteng batik khas Kulonprogo. Dimensi tinggi bangunan hampir dua kali tinggi manusia. Sementara di sisi kiri terdapat ikon gunungan wujud semboyan BINANGUN khas Kulonprogo.

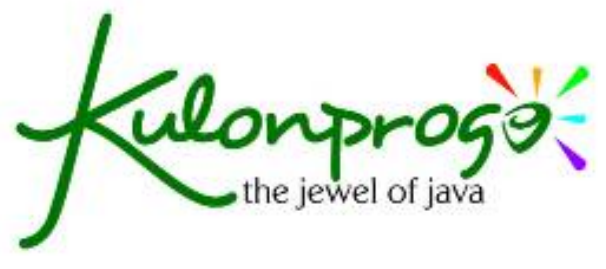

Gambar 9 Logo pariwisata Kulonprogo Sumber:

http://www.kulonprogokab.go.id/v21/pedomanbranding-kulon-progo-3_182_hal

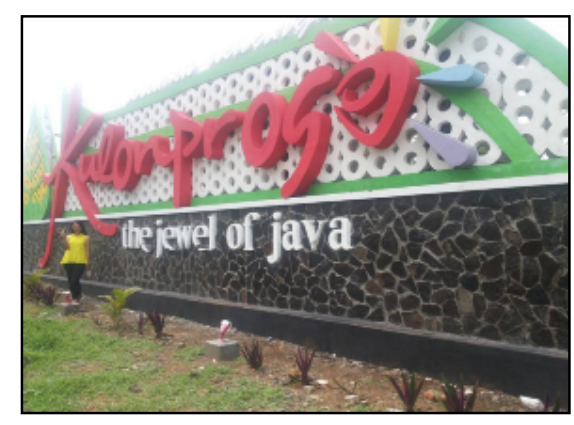

Gambar 10 Tipografi kawasan di dekat Jembatan Bantar, Sentolo, Kulonprogo.

Sumber: akun instagram @gertradishindiah, https://www.instagram.com/p/BAJ7wCQE2dI/ 


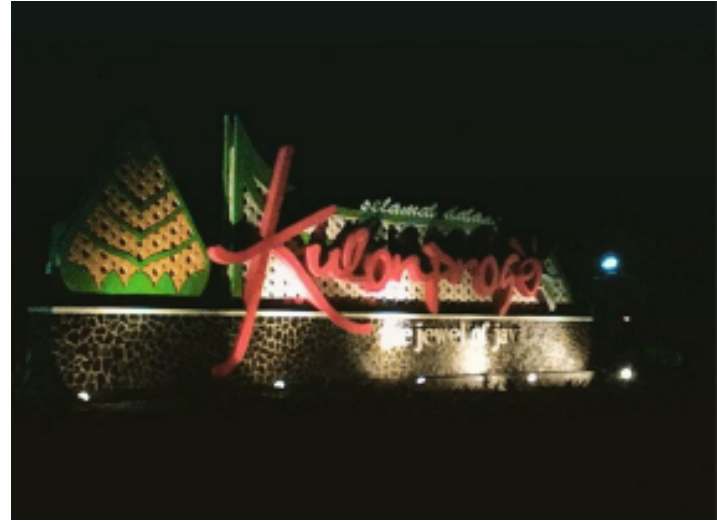

Gambar 11 Tipografi kawasan di dekat Jembatan Bantar, Sentolo, Kulonprogo.

Sumber: akun instagram @dee.puasta https://www.instagram.com/p/9eBAlInl_a/

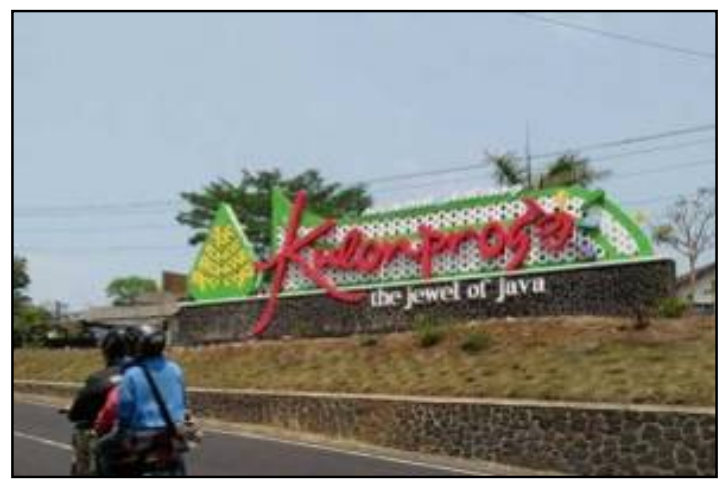

Gambar 12 Tipografi kawasan di dekat Jembatan Bantar, Sentolo, Kulonprogo.

Sumber:

http://www.harianjogja.com/baca/2015/11/04/kulonp rogo-the-jewel-of-java-menarik-perhatian-di-tepijalan-jogja-wates-658241

\section{Konteks Nonfisik (Rasa) dalam Fisik Arsitektural Tipografi Kawasan}

Uraian terkait konteks nonfisik tipografi kawasan ini lebih cenderung pada upaya menangkap esensi estetik dalam kesan tipografi kawasan yang penulis amati, yang berujung pada interpretasi karya tersebut, khususnya makna-makna konotatif karya tipografi kawasan. Upaya interpretasi ini mendapatkan bantuan metode analisis peak shift effect (efek perubahan yang tajam) dari Ramachandran dalam Marianto (2015: 210) yaitu melebih-lebihkan dan menyangatkan rasa (esensi, saripati, hakikat) atau aspek nonfisik yang tertampilkan secara kuat pada karya, dalam hal ini adalah tipografi kawasan. Rasa atau aspek nonfisik yang tadinya hanya dirasakan sang kreator, semula kecil, samar, tak terasa, lantas di-raksasa-kan agar terlihat jelas dan terasa kehadirannya melalui pengamatan karya tipografi kawasan.

Secara fisik, tampilan tipografi kawasan yang telah diwujudkan disesuaikan dengan kondisi tempat dan lingkungan di kawasan yang diakomodasikan. Dari segi komposisi dan estetik huruf, beberapa tipografi kawasan di tempat tertentu disajikan dari karakter visual (rupa huruf/typeface) elemen estetik huruf menunjukkan aura dan kesan formal, kaku, serius, kokoh, teratur, yang terlihat dari karakter visual jenis huruf serif dengan stroke (garis pada tubuh huruf) geometris, style kaku, bahkan cenderung berkarakter generik/umum, cenderung standar, bahkan mirip dengan tipografi kawan lain, dan ditata lurus horizontal, seperti pada tipografi kawasan bertuliskan "PARANGTRITIS" di Pantai Parangtritis yang penulis duga menyerupai typeface Times New Roman, dan tipografi kawasan bertuliskan “GUNUNGKIDUL” di gerbang daerah Patuk, Gunungkidul. Begitu pula tipografi kawasan bertuliskan "PUNCAK BUCU" di kawasan wisata Puncak Bucu, Piyungan, dengan jenis huruf sans serif menyerupai typeface Arial dengan style dan kesan yang serupa. Termasuk pula tipografi kawasan di Alun-Alun Wates Kulonptogo yang penulis duga menyerupai typeface Calibri, meski kesan dinamis diwujudkan dari italic style yang dihadirkan. Begitu pula kondisi yang kurang terawat dengan segala permasalahan yang telah disebutkan sebelumnya, misalnya tipografi 
kawasan Pantai Parangtritis, memunculkan kesan negatif atau bisa dibilang "rasa-rasanya" tipografi kawasan tersebut tak berarti.

Dipandang dari pendekatan disiplin Tipografi, dalam Rustan (2011: 108) karakter visual huruf memiliki "kepribadian/personality" yang dikandungnya sebagai analogi jiwa pada manusia. Sehingga pada dasarnya kajian ini membutuhkan kepekaan dan ketajaman intuisi dalam menganalisa hubungan antara karakter visual yang tampak dengan aspek keperibadian huruf yang ditangkap dalam kesan pengamat. Menurut penulis, karakter visual dan nonfisik (kesan/aura) jenis huruf serta penataan huruf yang demikian sesungguhnya secara psikologis justru bertolakbelakang dengan kesan dan nuansa konsep wisata yang ramah, fun, informal, santai, dan nyaman, yang digagas pemerintah. Meskipun karakter huruf yang sederhana seperti demikian memiliki tingkat legibility (kejelasan karakter huruf) dan readibility (keterbacaan) yang relatif tinggi. Dari sini peak shift effect dilihat dari personalitas huruf. Hal yang ingin dikedepankan adalah rasa (esensi) formal, kaku, serius, kokoh, teratur pada karakter visual huruf yang demikian justru bertolak belakang dengan konsep wisata yang ramah, fun/menyenangkan, informal, santai, dan nyaman, jauh dari kesan kaku dan formal.

$\mathrm{Hal}$ ini berbeda dengan tipografi kawasan di sekitar Jembatan Bantar Kulonprogo. Mengadaptasi logo pariwisata resmi, tipografi kawasan Kulonprogo di Jembatan Bantar, Sentolo, Kulonprogo, peak shift effect salah satunya digarap di wilayah tipografi dan unsur ikonik yang dihadirkan. Logotype (unsur huruf logo) pada tipografi kawasan dipakai untuk identitas wilayah
Kulonprogo, disajikan dengan huruf jenis display dengan karakter menyerupai tulisan tangan dan disintesis dengan berbagai ikon. Karakter huruf yang dinamis, stroke organik, contrast (tebal-tipis huruf) yang minim, dari logotype tersebut merefleksikan kesan dan nuansa wisata yang fun, ramah, informal, santai, dan nyaman. Selain itu, pada laman resmi Pemerintah Kabupaten (Pemkab) Kulonprogo

(http://www.kulonprogokab.go.id/), karakter logotype-nya juga merepresentasikan konsep dan filosofi logo, yaitu melambangkan potensi alami (natural), unsur etnisitas dan budaya yang dibalut kearifan lokal serta keluwesan untuk menerima perubahan dan pembaharuan yang mengembangkan daerah Kulonprogo. Pada tulisan Kulonprogo, memunculkan kesan untuk mengedepankan rasa (esensi) keramahan, menyenangkan, nuansa informal sebagai simbolisasi atas semangat branding Kulonprogo. Kendati unsur tipografi pada logo kawasan dibalut warna merah (bukan hijau sebagaimana warna logo utama aslinya), bisa jadi hal tersebut karena pertimbangan variasi warna identitas yang lazim dalam penerapan warna identitas (corporate color).

Peak shift effect pada tipografi kawasan Kulonprogo semakin nampak dalam filosofi, simbolisasi, dan metafora-metafora yang dipakai pada elemen visualnya. Mengingat tipografi kawasan tersebut mengejawantahkan logo dalam format tiga dimensional (3D). Maka tidak sekedar visual semata, berdasarkan laman Pemkab Kulonprogo (http://www.kulonprogokab.go.id/)

mengandung filosofi dan simbolisasi yang justru memberikan penyangatan - dan 
melebihkan rasa (esensi logo) sebagai tipografi kawasan yaitu:

"Pada dasarnya keseluruhan logo Kulon Progo melambangkan potensi alami (natural), unsur etnisitas dan budaya yang dibalut kearifan lokal serta dimanisasi atau keluwesan untuk menerima perubahan dan pembaharuan yang mengembangkan daerah Kulon Progo." Hal itu tampak pada: "Huruf "K" yang membentuk alur memanjang vertikal-horisontal seperti sebuah keris. Melambangkan Kulon Progo sebagai daerah yang kaya nilai kebudayaan dan kesenian jawa. Huruf " $K$ " yang juga memanjang ke bawah tulisan Kulon Progo mengibaratkan bahwa Kulon Progo memiliki kekayaan potensi alam yang dapat menopang kehidupan masyarakatnya.”

"Huruf "P" dengan lekuk yang tegas melambangkan kepala Elang Jawa menunjukkan nilai keteguhan, keberanian dan komitmen Kulon Progo sebagai daerah yang melindungi keanekaragaman hayati." "Huruf "G" dibuat mengesankan sisi kendi yang ada disetiap rumah di Kulon Progo. kendi merupakan perlambang keramahan, penerimaam, dan nilai kekeluargaan yang tumbuh dan berkembang dalam kultur kehidupan masyarakat Kulon Progo yang selalu menjunjung tinggi tradisi serta kebudayaan."

"Huruf "O" diakhir kata dimodifikasi menjadi bentuk permata dengan kilauan warna pelangi yang melambangkan potensipotensi yang dimiliki oleh Kulon Progo. Secara kesatuan melambangkan daerah Kulon Progo yang ibarat sebuah permata yang siap dikembangkan potensinya. Secara keseluruhan kulon Progo sebagai kesatuan wilayah dan masyarakatnya yang tak terpisahkan.”
Dari konsep logo pariwisata Kulon Progo sebagai tipografi kawasan di atas, jika diperjelas dengan konsep rasa dalam estetika India (Marianto, 2015: 207) dapat diuraikan sebagai berikut: Filosofi karakter visual huruf "K" dan "O" yang melambangkan nilai kebudayaan dan kesenian Jawa, serta kekayaan potensi alam, adalah menonjolkan rasa (esensi) adbhutan (esensi keajaiban dan keelokan) Kulon Progo; Filosofi karakter visual huruf "P" yang melambangkan nilainilai keteguhan, keberanian, dan komitmen, adalah menonjolkan rasa (esensi) viram (esensi kepahlawanan); Filosofi karakter visual huruf "G" yang melambangkan keramahan, penerimaan, dan nilai kekeluargaan, adalah menonjolkan rasa (esensi) karunyam (esensi cinta kasih dan keramahan) atau sringanam (esensi cinta dan kemenarikan), maupun santam (esensi kedamaian dan ketenangan).

Begitu pula peak shift effect digarap dari sisi background huruf yang bermotifkan batik khas Kulon Progo, yaitu motif geblek renteng, melambangkan kekayaan alam dan rasa persatuan masyarakat dalam membangun Kulon Progo. Motif geblek renteng adalah seperti ingin menonjolkan rasa (esensi) adbhutan (esensi keajaiban dan keelokan) dan santam (esensi kedamaian dan ketenangan) antar masyarakat Kulon Progo. Sebagaimana ditulis dalam laman Pemkab Kulonprogo (Error! Hyperlink reference not valid.) dan thehowdyindonesia.com, yaitu:

"Motif geblek renteng yang sudah menjadi
ikon Kulon Progo tersebut terdiri dari
gambar geblek sebagai motif utama dan
berbagai simbol yang menunjukkkan
kekayaan alam dan kondisi kabupaten
Kulon Progo. Geblek dijadikan motif utama
karena merupakan makanan asli khas karena merupakan makanan asli khas 
Kulon Progo. Geblek merupakan makanan yang merakyat, bentuknya yang digabunggabung (renteng) melambangkan masyarakat berdiri bersama-sama untuk membangun Kulon Progo. Bentuk Geblek yang menyerupai angka delapan melambangkan jika Kulon Progo memiliki 88 desa dan kelurahan."

Di samping itu, pada tipografi kawasan Kulonprogo tersebut terdapat simbolisasi semboyan BINANGUN (beriman, indah, nuhoni, aman, nalar, guyub, ulet, nyaman) yang digambarkan dalam simbol berbentuk gunungan. Dalam laman Pemkab Kulonprogo (http://www.kulonprogokab.go.id/), pada isian simbol tersebut terdapat stilasi gambar bunga berwarna kuning berjumlah 8 (delapan) yang merupakan simbolisasi 8 unsur dari motto BINANGUN yaitu: Beriman, Indah, Nuhoni, Aman, Nalar, Guyub, Ulet dan Nyaman; dan gambar kelopak daun berjumlah 5 (lima) berwarna hijau merupakan simbolisasi dari lima sila Pancasila Dasar Negara Republik Indonesia. Sehingga secara keseluruhan berarti bahwa Masyarakat dan Pemerintah Kabupaten Kulon Progo dalam membangun daerahnya, bertujuan agar menjadi lebih maju, makmur, sejahtera lahir bathin (Gunungan warna hijau dan kuning). Tujuan pembangunan dan cara mencapainya bersumber pada Pancasila dan UUD 1945 (kelopak daun 5 buah dan tempatnya).

Selain terkait pemaknaan tipografi dan ikonik, peak shift effect bisa juga dilihat dari konsep arsitektural bangunan tipografi kawasan tersebut. Beberapa tipografi kawasan berukuran raksasa yang memungkinkan tipografi kawasan tersebut menjadi point of interest dalam ruang publik suatu kawasan. Kucuran dana produksi yang tidak sedikit dan ukuran tipografi kawasan yang relatif besar memunculkan interpretasi akan kesungguhan pemerintah dalam branding pariwisata.

Dari segi fisik, umumnya material utama untuk pembuatan tipografi kawasan ini adalah logam/besi. Seperti elemen huruf pada tipografi kawasan di Parangtritis, dibuat dari plat logam (dilapisi anti karat) agar meminimalisir dampak korosi air laut yang diperkirakan tahan hingga 1,5 tahun. Bagian dudukan hurufnya di-cor beton, agar tetap berdiri kokoh. Barangkali ini juga mempertimbangkan kondisi kawasan Parangtritis yang sewaktu-waktu bisa dilanda angin kencang. Kokohnya bangunan ini memunculkan kesan akan jaminan keamanan untuk masyarakat yang mengabadikan momen di sekitar tipografi kawasan tersebut.

Namun, kondisi buruk tersebut pernah terjadi, pada 20 Februari 2015, Kedaulatan Rakyat mewartakan bahwa angin kencang merusak tipografi kawasan di Pantai Parangtritis (http://krjogja.com/read/249499/ wisatawan-minta-kerusakan-segera-

diperbaiki.kr). Pengunjung yang penasaran dan berniat mengabadikan momen di sekitarnya, merasa kecewa melihat kondisi tipografi kawasan yang rusak. Hal ini tentunya perlu diingat, insiden tersebut di luar kuasa manusia. Namun tetap harus menjadi pelajaran bagi pemerintah Bantul sendiri dan pemerintah wilayah lainnya yang bermaksud membangun tipografi kawasan, perlu mempertimbangkan kekuatan material dengan kondisi geografis dan alam. 


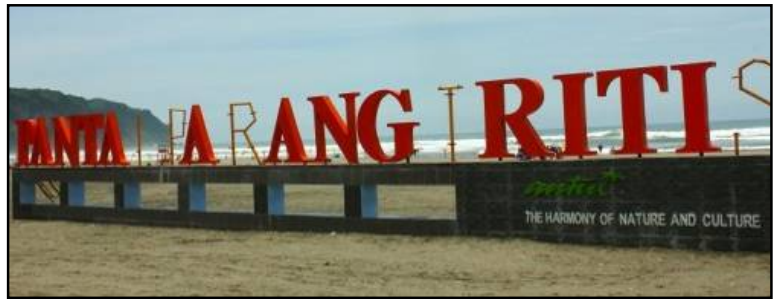

Gambar 13 Tipografi kawasan di Parangtritis yang rusak akibat angin kencang

Sumber: http://krjogja.com/read/249499/wisatawanminta-kerusakan-segera-diperbaiki.kr

Berbeda jika tipografi kawasan tersebut sengaja dibuat dari bahan yang mudah ambruk, rubuh, rusak, maka akan memunculkan persepsi publik yang buruk atas brand image pengelola dan pemerintah. Maksud hati ingin menarik wisatawan dengan adanya landmark tersebut, namun karena dianggap membahayakan, akhirnya wisatawan enggan mendekat. Sehingga dapat berpengaruh pada rusaknya brand image yang memunculkan pandangan bahwa pemerintah tidak profesional dan kurang memberikan pelayanan yang sungguh-sungguh dan terbaik untuk kemajuan pariwisata lokal.

\section{Dampak Sosio-Kultural (sebuah studi kasus)}

Kenyataannya, selain untuk menarik calon wisatawan agar berkunjung datang ke wilayah tertentu, tipografi kawasan tersebut pun kemudian menjadi obyek wisata baru yang menjadi magnet tersendiri. Misalnya tipografi kawasan di pinggir jalan sekitar gerbang Patuk (pintu masuk YogyakartaWonosari) yang penulis amati, menjadi tempat transit favorit baru dan istimewa bagi wisatawan yang akan melanjutkan perjalanan ke Gunungkidul, untuk mengambil gambar (foto) di sekitar tipografi kawasan tersebut. Tipografi kawasan sebagai public art dalam ruang publik (public space) kemudian menjadi ruang kultur (culture space) baru, menciptakan nilai baru, memunculkan trend baru bagi masyarakat untuk berlomba-lomba mengabadikan momen berlatarbelakang tipografi kawasan tersebut.

Resikonya, pada kasus sosio-kultural di atas, tak jarang terjadi kemacetan lalu lintas sebagai ekses negatif bangunan tipografi kawasan di jalur gerbang Patuk yang menyedot perhatian masyarakat. Bahkan belum adanya tempat parkir yang memadai berdampak pada pola dan perilaku wisatawan yang terkadang cenderung sembarang parkir di bahu jalan. Mengingat kawasan tersebut merupakan jalur utama lalu lintas menuju Gunungkidul yang cenderung ramai dan tanjakan, dampak yang demikian sangat membahayakan. Sehingga pengelola atau pemerintah perlu memikirkan dampak sosiokultural dari pembangunan tipografi kawasan arsitektural tersebut. Kendati sebenarnya area sekitar Tipografi kawasan tersebut bukan untuk rest area.

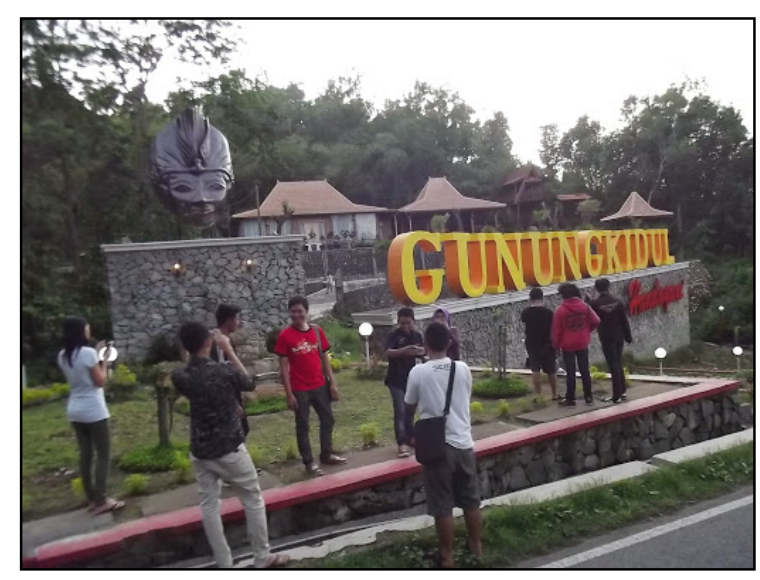

Gambar 14 Tipografi kawasan di gerbang Patuk Gunungkidul Sumber:

http://www.bismania.com/home/showthread .php? $\mathrm{t}=13703$ \&page $=12$ 


\section{Permasalahan Estetis Tipografi Kawasan}

Seperti halnya di berbagai daerah lain di Indonesia, geliat munculnya fenomena landmark tipografis seolah-olah mempertontokan gemuruh daerah-daerah di DIY yang berlaga merebut hati calon wisatawan. Namun, kesadaran akan penampilan dan aura identitas sebagai daya tarik sebagaimana yang diuraikan sebelumnya seperti kurang dipahami betul, terutama nampak dari beberapa penciptaan karya-karya landmark tipografis di beberapa wilayah DIY. Hal ini mengingatkan penulis pada pernyataan Riber dalam Rowland (2008: 66-67), yang umumnya orang terjebak pada penciptaan formalistik atau bisa dibilang terjebak bentukbentuk objek seni semata, bukan menekankan terhadap kualitas dan substansi dari karya seni itu sendiri, dalam hal ini tipografi kawasan.

Dalam konteks tipografi kawasan sebagai identitas tipografis (visual), beberapa kasus tipografi kawasan di beberapa tempat, didesain dengan typeface yang generik (umum), bukan direncanakan dan dirancang secara unik atau khusus untuk merespon permasalahan komunikasi visual kawasan itu sendiri. Sebagai contoh tipografi kawasan di Pantai Parangtritis (jenis huruf serif /huruf berkait, menyerupai typeface Times New Roman), dan di kawasan gerbang utama Kabupaten Gunungkidul (jenis huruf serif), Puncak Bucu (jenis huruf sans serif /tidak berkait, menyerupai typeface Arial), dan AlunAlun Wates (jenis huruf sans serif menyerupai typeface Calibri).

Bahkan di beberapa tempat tersebut (di Pantai Parangtritis dan Gerbang Patuk), desain landmark semacam ini cenderung mirip dan serupa karena karakter artistik tipografinya yang terlampau umum, dan tidak mencerminkan keunikan entitas (wilayah). Sebagai studi komparasi umum saja, karakter typeface-nya tidak hanya cenderung mirip antar kawasan di DIY bahkan di kota-kota lainnya di Indonesia, misalnya di Pantai Losari Makassar (jenis huruf serif, menyerupai typeface Times New Roman). Sehingga penulis berupaya merumuskan asumsi analitis terhadap fenomena permasalahan ini didasarkan pada pembacaan wacana atas praktik tipografi kawasan tersebut.

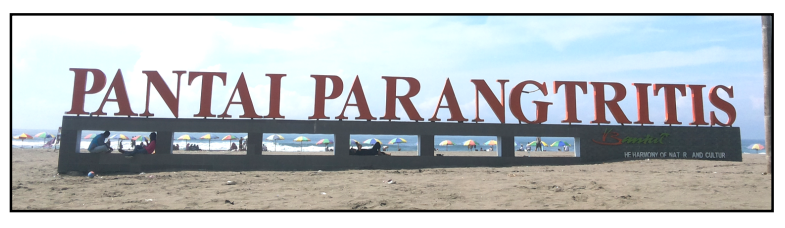

Gambar 15 Tipografi kawasan di Pantai Parangtritis Foto: Naufan Noordyanto, 2015

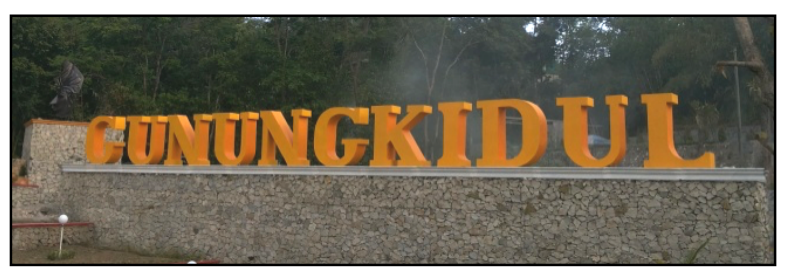

Gambar 16

Gambar . Tipografi kawasan di gerbang Patuk Gunungkidul

Foto: Naufan Noordyanto, 2014

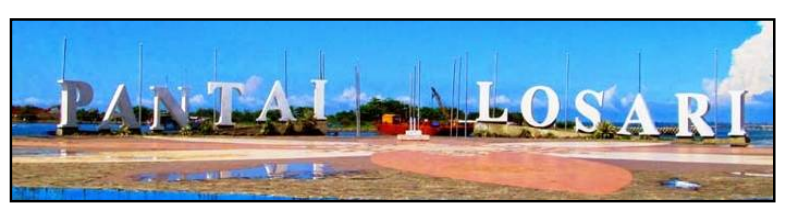

Gambar 17 Tipografi kawasan di Pantai Losari Makassar Sumber:

http://anekawisatanusantara.blogspot.com/2015/03/w isata-pantai-losari-makassar.html

Pertama, pemilihan dan penggunaan typeface yang terlampau generik, cenderung standar, bahkan mirip dengan tipografi kawan lain, mengindikasikan minimnya upaya kreatif 
berupa riset kemiripan dengan identitas landmark tipografis lain. Permasalahan ini bukan soal upaya menghias huruf saja, tetapi sekaligus mengisyaratkan sikap abai terhadap eksplorasi visualisasi kreatif merupa huruf yang mengakomodasi solusi komunikasi dan representasi kota. Padahal dalam branding, keserupaan merupakan lawan dari keunikan. Hakikat identitas adalah meniscayakan adanya keterbedaan. Sehingga desain landmark tipografi dengan karakteristik bentuk dan visual yang berbeda dan unik itu menjadi spesial atau istimewa.

Keniscayaan identitas visual landmark tipografis tersebut seharusnya disajikan berbeda, unik, dan khas sesuai keperibadian dan konsep nilai entitas kawasan yang khas pula. Hal ini juga karena terkait positioning yang menuntut persaingan identitas brand untuk masuk dan diingat dalam memori otak target audiens. Identitas visual yang berbeda, khas, unik, tentu saja berpeluang besar memenangkan laga tersebut, yang berdampak positif pada awareness wisatawan untuk menjadikan kota tersebut pilihan tepat sebagai tempat yang nyaman dikunjungi. Sementara, keserupaan dengan identitas lain akan mengurangi awareness terhadap brand wilayah di kalangan masyarakat.

Kedua, kemiripan rupa huruf ini rupanya juga akibat "terinspirasi" dari pembuatan tipografi kawasan di berbagai wilayah. Salah satunya, seperti dilansir Kedaulatan rakyat pada Senin, 15 Desember 2014 (http://krjogja.com/read/ 240899/ horeparangtritis-punya-ikon-baru.kr), Kepala Dinas Kebudayaan dan Pariwisata (Disbudpar) Kabupaten Bantul, Bambang Legowo menyampaikan bahwa pemilihan dan pembuatan tipografi kawasan tersebut menilik kawasan lain, seperti di Pantai Losari terdapat ikon berupa tulisan yang banyak diminati wisatawan. Hal ini kemudian memunculkan asumsi lanjut bahwa keberadaannya merupakan bentuk fenonema "latah", yang meniru berbagai praktik penciptaan tipografi kawasan di berbagai daerah lain di Indonesia.

Ketiga, masalah ini muncul karena beberapa tempat belum memiliki identitas visual secara mandiri dan resmi. Pembangunan tipografi kawasan Gunungkidul misalnya, dibuat sebelum logo pariwisata yang baru-baru ini (2015) diresmikan. Akibatnya kini, antara logo pariwisata daerah dan tipografi kawasan Gunungkidul tidak mengejawantahkan konsep konsistensi penerapan identitas. Berbeda dengan upaya pemerintah Kulon Progo yang membuat tipografi kawasan di sekitar jembatan Banjar setelah pembuatan logo pariwisatanya. Demikian pula kasus pada tipografi kawasan Parangtritis, Puncak Bucu Piyungan dan Alun-Alun Wates Kulon Progo yang juga tidak memiliki identitas visual secara mandiri.

Keempat, hasil eksekusi tipografi kawasan yang demikian seperti ingin menunjukkan pandangan pragmatis instan: "yang penting ada untuk penanda nama wilayah, daripada tidak ada sama sekali". Tipografi kawasan atau landmark tersebut bisa jadi hanya dianggap sekedar pemanis ruang publik, hanya fisik semata, sehingga aspek nonfisiknya (ruh/aura) sebagai cerminan keperibadian dan brand image wilayah kurang disadari, terlebih dirasa tidak diperlukan citra apa-apa lagi selain fungsinya sebagai instrumen identifikasi dan penghias tata wilayah. Memang, jika identitas kota yang diwakili pada landmark tipografis hanya 
"di(paksa)fungsikan" untuk mengidentifikasi wilayah atau kawasan saja dengan estetika dan konsep seadanya, maka ia hanya berfungsi sekedar sebagai penanda nama kawasan tersebut. Namun jika visualisasi (elemen estetik) tipografi kawasan membentuk dan mewakili nilai-nilai dan citra kawasan tersebut, maka ia akan menjadi layaknya "merek yang menjual" atas upaya branding kawasan tersebut.

Kelima, fakta bahwa keberadaannya merupakan proyek kebijakan strategis dalam membangun image destinasi wisata, maka dapat dikatakan karya tipografi kawasan adalah (desain) produk kebijakan politis dari pemerintah sebagai regulator dan pemegang kekuasaan wilayah (administratif). Sebagai kebijakan politis, terutama dalam ranah politik praktis, ia berfungsi sebagai salah satu sarana pemandu dan mempengaruhi kepekaan sosial terkait "brand awareness" potensi wisata wilayah. Motifnya adalah kepentingan pragmatis ekonomi, terutama dalam upaya merangkul pasar wisatawan nasional dan internasional. Mengamati fenomena ini, sependapat dengan yang disampaikan Weber (2009: 278) tentang "posisi kekuasaan birokrasi yang biasanya selalu tinggi", menurut penulis, keputusan kreatif perencanaan desain tipografi kawasan bergantung pada pemilik otoritas tertinggi (birokrasi dan kekuasaan/politik). Sehingga penulis berasumsi bahwa wacana estetika yang dimunculkan merefleksikan estetika (pengaruh) politik ekonomi pemerintah.

Karena itu, dari segi komposisi dan estetik huruf, beberapa tipografi kawasan di tempat tertentu disajikan dari karakter visual (rupa huruf/typeface) elemen estetik huruf menunjukkan aura dan kesan formal, kaku, serius, kokoh, teratur, yang terlihat dari karakter visual jenis huruf serif dengan stroke (garis pada tubuh huruf) geometris, style kaku, bahkan cenderung berkarakter generik/umum dan ditata lurus horizontal, seperti pada tipografi kawasan bertuliskan “PARANGTRITIS” di Pantai Parangtritis yang penulis duga menyerupai typeface Times New Roman, dan tipografi kawasan bertuliskan "GUNUNGKIDUL" di gerbang daerah Patuk. Begitu pula tipografi kawasan bertuliskan "PUNCAK BUCU" di kawasan wisata Puncak Bucu, Piyungan, dengan jenis huruf sans serif menyerupai typeface Arial dengan style dan kesan yang serupa. Dipandang dari pendekatan disiplin Tipografi menurut Rustan (2011: 108) yang menganggap bahwa setiap karakter huruf memiliki "kepribadian/personality" yang dikandungnya sebagai analogi jiwa pada manusia, karakter visual dan nonfisik (kesan/aura) jenis huruf serta penataan huruf yang demikian sesungguhnya secara psikologis justru bertolakbelakang dengan kesan dan nuansa wisata yang ramah, fun, informal, santai, dan nyaman. Meskipun karakter huruf yang sederhana seperti demikian memiliki tingkat legibility (kejelasan karakter huruf) dan readibility (keterbacaan) yang relatif tinggi.

Hal ini berbeda dengan tipografi kawasan di sekitar Jembatan Bantar Kulon Progo. Mengadaptasi logo pariwisata resmi, logotype (unsur huruf logo) pada tipografi kawasan dipakai untuk identitas wilayah Kulon Progo, disajikan dengan huruf jenis display dengan karakter menyerupai tulisan tangan dan disintesis dengan berbagai ikon. Karakter huruf yang dinamis, stroke organik, contrast (tebal-tipis huruf) yang minim, dari logotype tersebut merefleksikan kesan dan 
nuansa wisata yang fun, ramah, informal, santai, dan nyaman. Selain itu, pada laman resmi Pemerintah Kabupaten (Pemkab) Kulon Progo (http://www.kulonprogokab.go.id/), karakter logotype-nya juga merepresentasikan konsep dan filosofi logo, yaitu melambangkan potensi alami (natural), unsur etnisitas dan budaya yang dibalut kearifan lokal serta keluwesan untuk menerima perubahan dan pembaharuan yang mengembangkan daerah Kulon Progo.

Masih terkait susunan huruf, secara teknikal terdapat beberapa permasalahan kerning atau pengaturan jarak antar huruf (letter spacing) yang tidak tersusun harmonis secara optis. Sebagai contoh, perhatikan space (ruang) di antara huruf "N" dan "G" pada tulisan tipografi kawasan di Patuk, Gunungkidul, yang secara optis, pengaturan jarak seperti ini kurang proporsional. Karena efek bowl (stroke yang berbentuk lengkung/melingkar) membentuk space yang relatif lebih besar dan tidak pas di antara huruf " $N$ " dan " $G$ " dibandingkan dengan dengan space antara huruf "G" dan "K", di antara terminal (ujung stroke) berbenruk barbed (mata kail sebagai serif) pada huruf " $G$ " dengan serif dan stroke tegak huruf " $\mathrm{K}$ ". Sehingga perlu dilakukan penyesuaian jarak ulang, misalnya dengan lebih merapatkan huruf "N" dan "G" tersebut. Penyesuaian optis letter spacing seperti ini sangat penting dalam menyusun antar huruf tipografi kawasan, agar terlihat proporsional, harmonis, enak dilihat maupun dibaca, serta tidak memakan tempat berlebih.

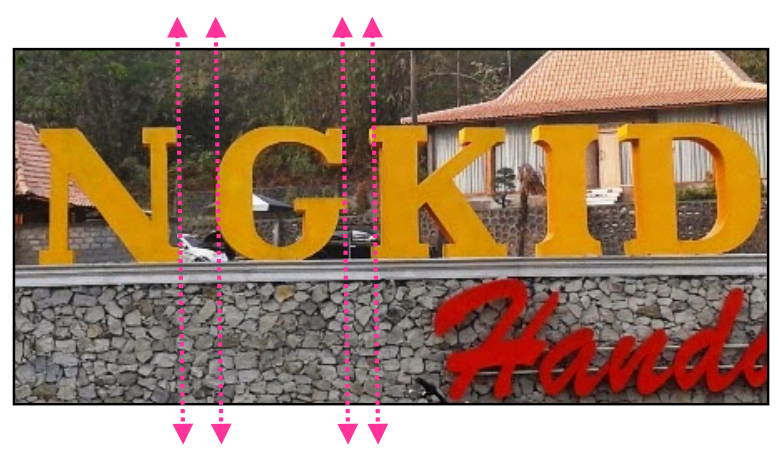

Gambar 18 Permasalahan optis pada susunan huruf tipografi kawasan Gunungkidul

Sumber: http://www.nasirullahsitam.com/2014/12/ mengayuh -pedal-sepeda-ke-embung.html

\section{KESIMPULAN DAN SARAN}

Pada dasarnya, melihat fakta empiris di lapangan, tipografi kawasan sebagai tipografi spasial 3D, merupakan perangkat visual branding yang penting keberadaaannya bagi suatu kawasan atau wilayah. Tidak hanya untuk mengidentifikasi kawasan atau wilayah, tipografi kawasan sebagai identitas idealnya diciptakan untuk memberikan gambaran tentang brand image bagaimana kawasan atau wilayah tersebut ingin dipersepsikan oleh masyarakat. Maka, tipografi kawasan sejatinya memiliki dualitas nilai, yaitu nilai materil/inderawi dengan kemampuannya sebagai identitas fisik yang dapat dilihat (karakteristik visual); dan nilai immateril/abstrak melingkupi berupa aura/kesan (psikologis), citra (brand image), asosiasi makna, simbolisasi, metafora, representasi nilai-nilai, dll.

Kenyataannya, praktik tipografi kawasan di salah satu lokasi di DIY yang ditemukan penulis, menerapkan identitas visual (logo) resmi pariwisata wilayah seperti di Jembatan Bantar Gunungkidul sehingga karakter visual, konsep, asosiasi nilai-nilai, dan 
representasi, mengadaptasi logo pariwisata tersebut. Sementara di beberapa kawasan DIY lain, seperti di Pantai Parangtritis dan Gunungkidul, bahkan dengan kawasan lain misalnya Pantai Losari sebagai pembanding dari luar DIY, menerapkan penggunaan typeface yang terlampau generik, cenderung standar, bahkan memiliki kemiripan antara kawasan dan wilayah satu dengan lainnya.

Penulis memandang permasalahan tersebut karena minimnya pemahaman dan kesadaran akan pentingnya penampilan estetik (fisik/visual) dan aspek nonfisik (ruh/aura) identitas sebagai daya tarik komunikatif. Padahal, jika visualisasi (elemen estetik) tipografi kawasan merepresentasikan nilai-nilai dan citra kawasan tersebut, maka ia akan menjadi layaknya "merek yang menjual" atas upaya branding kawasan tersebut. Selain itu, jika tipografi kawasan dibuat dengan (konsep) estetika yang baik dan memenuhi fungsi-fungsi sebagai karya desain identitas branding kawasan atau wilayah, ia akan dapat dilihat, dinikmati, serta dinikmati keindahaan dan kemenarikannya secara mandiri sebagai karya public art, bahkan dapat menarik perhatian wacana seni dan tipografi.

Secara teknis, dimensi estetik huruf sebaiknya tidak bersifat generik dan memakai jenis huruf standar, mengingat juga dipakai di kawasan lain, sehingga harus tampil beda dengan kekhasan dan keunikannya, agar mudah diingat. Maka penting melakukan riset identitas, kemiripan, keunikan, dan eksplorasi visual tipografi kawasan. Namun, jika sudah ada identitas visual wilayah yang resmi, maka identitas visual tersebut bisa diterapkan dalam pembuatan bangunan landmark tipografis. Komposisi huruf pun demikian, tidak harus ditata horizontal, bisa menerapkan penataan diagonal, vertikal, sesuai dengan kondisi dan solusi lokasi (lingkungan/kawasan). Baik dimensi estetis dan komposisi susunan huruf akan berpengaruh pada kesan (psikologis) dan kekuatan/aura sebagai daya tarik wisatawan terhadap kawasan tersebut. Sekaligus merefleksikan brand image yang dikomunikasikan secara tersirat pada karakter fisik dan visual.

Citra (brand image) destinasi wisata mestinya mampu digambarkan melalui aura dimensi estetik (visual) yang dipancarkan dari desain Tipografi kawasan tersebut. Dengan menelan dana yang tidak sedikit, seharusnya ia dirancang unik, memorable, spesial, khas /destinctive, menarik, matang secara teknikal dan konspetual, serta baik dari segi estetik tipografis dan arsitektural. Visualisasi tipografi kawasan yang demikian dibuat agar mampu membentuk eskpektasi pada wisatawan akan gambaran kondisi positif, spesial, khas, unik, dan menarik tentang destinasi kawasan/daerah yang dikunjunginya. Sekaligus menjanjikan sajian pengalaman yang berkualitas, unik, dan mengesankan atas kunjungan yang akan dilakukan sehingga calon wisatawan akan tertarik (Dewi, 2009: 123).

\section{DAFTAR PUSTAKA}

\section{Buku:}

[1] Calori, Chris. Vanden-Eynde, David. 2015. Signage and Wayfinding Design. New Jersey: John Wiley \& Sons, Inc.

[2] Dewi, Ike Janita. 2009. Creating \& Sustaining Brand Equity: Aspek Manajerial dan Akademis dari Branding. Yogyakarta: Amara Books

[3] Klimchuk, Marianne Rosner dan Krasovec, Sandra A. Packaging Design: Successful Product Branding from Concept 
to Shelf. New Jersey: John Wiley \& Sons, Inc.

[4] Rowland, Susan. 2008. Psyche and the arts: Jungian approaches to music, architecture, literature, film, and painting. New York: Routledge

[5] Rustan, Surianto. 2011. Font \& Tipografi. Jakarta: PT. Gramedia Pustaka

[6] Simamora, Bison. 2002. Aura Merek. Jakarta: PT. Gramedia Pustaka Utama

[7] Tim Penyusun Kamus Pusat Bahasa. 2008. Kamus Bahasa Indonesia. Jakarta: Pusat Bahasa Departemen Pendidikan Nasional

[8] Yananda, M. Rahmat, dan Salamah, Ummi. 2014. Branding Tempat: Membangung Kota, Kabupaten, dan Provinsi Berbasis Identitas. Jakarta Selatan: Makna Informasi

[9] Weber, Max. 2009. Sosiologi. Yogyakarta: Pustaka Pelajar

\section{Internet:}

[1] Anekawisatanusantara. (25 Maret 2015 ). Wisata Pantai Losari Makassar. [Online] Tersedia: http://anekawisatanusantara. blogspot.com/2015/03/wisata-pantailosari-makassar.html. Diakses pada 9 November 2015, pukul 20:28 WIB

[2] Encyclopædia Britannica. [Online] Tersedia: http://www. britannica.com/science/regiongeography, Diakses pada 11 November 2015, pukul 18:15 WIB

[3] Forum bismania. [Online] Tersedia: http://www.bismania.com/home/showthr ead.php? $\mathrm{t}=13703$ \&page $=12$. $\quad$ Diakses pada 10 November 2015, pukul 13:21 WIB

[4] Kabarhandayani.com. (13 Juli 2014). Ikon Baru GUNUNGKIDUL Handayani Sambut Wisatawan. [Online] Tersedia: http://kabarhandayani.com/ikon-barugunungkidul-handayani-sambut- wisatawan-2/. Diakses pada 8 November 2015, pukul 12:43 WIB

[5] Pemerintah Kabupaten Kulon p\#rogo. Pedoman Branding Kabupaten Kulon Progo. [Online] Tersedia: http://www.kulonprogokab.go.id/v21/ide ntitas-daerah_10_hal. Diakses pada 8 November 2015, pukul 09:20 WIB

[6] Radar Jogja. (17 Desember 2014). Tulisan Raksasa Jadi Daya Tarik Wisatawan. [Online] Tersedia:_Error! Hyperlink reference not valid.. Diakses pada 7 November 2015, pukul 13:20 WIB

[7] Sitam, Nasirullah. (Desember 2014) Mengayuh Pedal Sepeda ke Embung Nglanggeran, Gunungkidul. [Online] Tersedia: Error! Hyperlink reference not valid.. Diakses pada 8 November 2015, pukul 10:00 WIB

[8] Thehowdyindonesia.com. (21 Oktober 2012). [Online] Tersedia: http://www.thehowdyindonesia.com/201 2/10/filosofi-batik-geblek-renteng.html. Diakses pada 2 Januari 2016, pukul 08:30 WIB

[9] Widiyanto, Danar. Kedaulatan Rakyat.(15 Desember 2014). Hore.. Parangtritis Punya Ikon Baru. [Online] Tersedia: http://krjogja.com/ read/ 240899/hore-parangtritis-punya-ikonbaru.kr. Diakses pada 7 November 2015, pukul 09:45 WIB

[10] Widianto, Danar. Kedaulatan Rakyat. (20 Februari 2015) Kedaulatan Rakyat. Wisatawan Minta Kerusakan Segera Diperbaiki. [Online] Tersedia: http://krjogja.com/read/249499/wisatawa n-minta-kerusakan-segera-diperbaiki.kr. Diakses pada 7 November 2015, pukul 09:30 WIB

\section{Media sosial (instagram):}

[1] @bay157extrada. https://www.instagram.com/p/_x9t5QpT u9/ 
[2]@dee.puasta.

https://www.instagram.com/p/9eBAlInl_

a/

[3] @gertradishindiah.

https://www.instagram.com/p/BAJ7wCQ

E2dI/

[4]@filiphusjohandemey.

https://instagram.com/p/9qJAF1CmH1/

[5]@mas_isna. https://instagram.com/ p/9rvTVgLYYz/

[6]@mheylhya.

https://www.instagram.com/p/_wPtJ3Ec

$\mathrm{X} 9$ /

[7]@muhammad.faliq. https://instagram.com/p/ 9DioJLHQ3R/

[8]@narko_dwi.

https://www.instagram.com/p/_wfSX1Tc

$\mathrm{zn} /$

[9] @syrfdn. https://instagram.com/p/ 9xUoXons6X/

[10] @tina_lastafala.

https://www.instagram.com/p/-

uXqDEPvDg/ 